\title{
Sciatic nerve block in the popliteal fossa: description of a new medial approach
}

\section{[Le bloc du nerf sciatique dans le creux poplité : une nouvelle approche médiale]}

Emmanuel Guntz MD,${ }^{*}$ Pierre Herman MD, ${ }^{*}$ Eric Debizet MD,${ }^{*}$ Damien Delhaye MD, $\dagger$ Very Coulic MD,${ }^{*}$ Maurice Sosnowski MD PhD*

Purpose: Sciatic nerve blocks through lateral approaches in the popliteal fossa have been proposed. We describe a new medial approach to the sciatic nerve at this level.

Methods: After an anatomical study on six cadavers, we performed sciatic nerve blocks on 20 patients. A 100-mm insulated needle and a nerve stimulator were used; $20 \mathrm{~mL}$ of lidocaine $1.5 \%$ with epinephrine were injected.

Results: Patients lied in the supine position, the thigh flexed, abducted and rotated externally ( $30^{\circ}$ in all directions). The leg was flexed at $130^{\circ}$. In this position, above the adductor tubercle, a depression known as Jobert's fossa is palpated. Through this groove, a medial approach to the sciatic nerve at the level of the popliteal fossa is possible. The mean distance between the adductor tubercle and the puncture site is $6.18 \mathrm{~cm}$ (range $4-8 \mathrm{~cm}$ ) and the mean distance between the skin and the sciatic nerve is 6.62 $\mathrm{cm}$ (range 4-9 cm). Mean time to perform the block was $100 \mathrm{sec}$ (range 55-165 sec). Complete motor blockade was obtained after a mean time of $30 \mathrm{~min}$ (range 5-60 min) inside the common peroneal nerve area and $43 \mathrm{~min}$ (range 15-75 min) inside the tibial nerve area. Motor block was complete in 17 patients and sensory block in 18 patients. No vessel puncture was observed.

Conclusion: We describe a new medial approach to the sciatic nerve in the popliteal fossa. More studies will be required to demonstrate the technique is effective and safe.

Objectif : Des blocs du nerf sciatique par des approches latérales du creux poplité ont été proposés. Nous décrivons une nouvelle approche médiale du nerf sciatique à ce niveau.

Méthode : Après une étude anatomique sur six cadavres, nous avons réalisé des blocs du nerf sciatique sur 20 patients. Une aiguille isolée de $100 \mathrm{~mm}$ et un neurostimulateur ont été utilisés ; $20 \mathrm{~mL}$ de lidocaïne à 1,5\% avec épinéphrine ont été injectés.
Résultats : Les patients étaient étendus décubitus dorsal, la cuisse fléchie, en abduction et en rotation vers l'extérieur (de $30^{\circ}$ dans toutes les directions). La jambe était fléchie à $130^{\circ}$. Dans cette position, une dépression connue sous le nom de fosse de Jobert est palpée au-dessus du tubercule de l'adducteur. Par ce sillon, une approche médiale du nerf sciatique est possible au niveau du creux poplité. La distance moyenne entre le tubercule de l'adducteur et le site de ponction est de 6, $18 \mathrm{~cm}$ (limites $4-8 \mathrm{~cm}$ ) et la distance moyenne entre la peau et le nerf sciatique est de 6,62 cm (limites 4-9 cm). Le temps moyen nécessaire pour réaliser le bloc a été de $100 \mathrm{sec}$ (limites $55-165 \mathrm{sec}$ ). Le blocage moteur complet a été obtenu après un temps moyen de 30 min (limites 5-60 min) dans la zone du nerf sciatique poplité externe et de 43 min (limites 15 -75 min) dans la zone du nerf tibial. Le bloc moteur a été complet chez 17 patients et le bloc sensitif chez 18 patients. Aucune ponction vasculaire n'a été observée.

Conclusion : Nous décrivons une nouvelle approche médiale du nerf sciatique dans le creux poplité. II reste à démontrer l'efficacité et la sécurité de la technique.

From the Departments of Anesthesiology, ${ }^{*}$ and Radiology, $†$ Université Libre de Bruxelles, C.H.U Saint-Pierre, Brussels, Belgium. Address correspondence to: Dr. Emmanuel Guntz, Anesthesiology Department, C.H.U. Saint-Pierre, rue Haute, 322, Brussels, 1000 Belgium. Phone: 003225353593; Fax: 003225354070; E-mail: eguntz@ulb.ac.be Address requests for reprints to: Dr. Maurice Sosnowski, Anesthesiology Department, C.H.U. Saint-Pierre, rue Haute, 322, Brussels,

1000, Belgium. Phone: 003225353593; Fax: 003225354070; E-mail: maurice_sosnowski@stpierre-bru.be Accepted for publication January 27, 2004.

Revision accepted April 26, 2004. 


\section{Methods}

Dissections of six lower limbs from six cadavers were performed at the level of the medial thigh region. We first measured the superficial landmarks. Then we measured the skin-sciatic nerve and the popliteal vessel-sciatic nerve distances.

Following these anatomical investigations, we designed a new approach to block the sciatic nerve. The Medical Ethics Committee approved this prospective study and written informed consent was obtained from 20 patients, ASA physical status I to III. Patients received standard monitoring and were sedated with midazolam 1 to $2 \mathrm{mg} i v$. After skin disinfection, a 22gauge insulated $100-\mathrm{mm}$ needle (Stimuplex A Braun, D-34209 Melsungen, Germany) was used. The nerve stimulator (Stimuplex HNS 11, Braun D-34209 Melsungen, Germany) variables were initially set at $\mathbf{1 . 5}$ $\mathrm{mA}, 2 \mathrm{~Hz}, 0.1 \mathrm{msec}$. When motor responses were obtained (plantar flexion of the foot for the tibial nerve, dorsal flexion of the foot for the common peroneal nerve), nerve stimulation was progressively decreased to $0.5 \mathrm{~mA}$. After careful aspiration and a $1-\mathrm{mL}$ test dose, $20 \mathrm{~mL}$ of local anesthetic (lidocaine 1.5\% with epinephrine $1: 200,000)$ were injected. In addition a saphenous nerve block was always performed under the knee $(5 \mathrm{~mL}$ of the same local anesthetic).

We measured both the adductor tubercle-puncture site and the skin-sciatic nerve distances. We recorded the time to perform the block and the motor responses (tibial or peroneal). Sensory block onset times were checked after five, ten, 20,30,45, 60, $75 \mathrm{~min}$ by a pinprick test (needle of a Dejerine's reflex hammer, neurologicals 5038) and a cold test in the following territories: tibial nerve, common peroneal nerve and medial cutaneous sural nerve. Motor block onset times were checked at the same time (plantar flexion of the foot for the tibial nerve, dorsal flexion of the foot for the common peroneal nerve). Patients were randomly allocated to one of the two first authors (experienced anesthesiologists). Randomization was performed with the random permuted block method.

Patients were asked to classify the procedure in one of three categories: no discomfort, unpleasant, painful.

\section{Results}

Anatomical results

When the thigh is flexed, abducted, rotated externally $\left(30^{\circ}\right.$ in the three directions) and the leg flexed at $130^{\circ}$ (Figure 1), a groove, known as Jobert's fossa, is palpated between the sartorious and the gracilis muscles posteriorly and the vastus medialis muscle anteriorly (Figures 2 and 3 ). This fossa is limited above by the

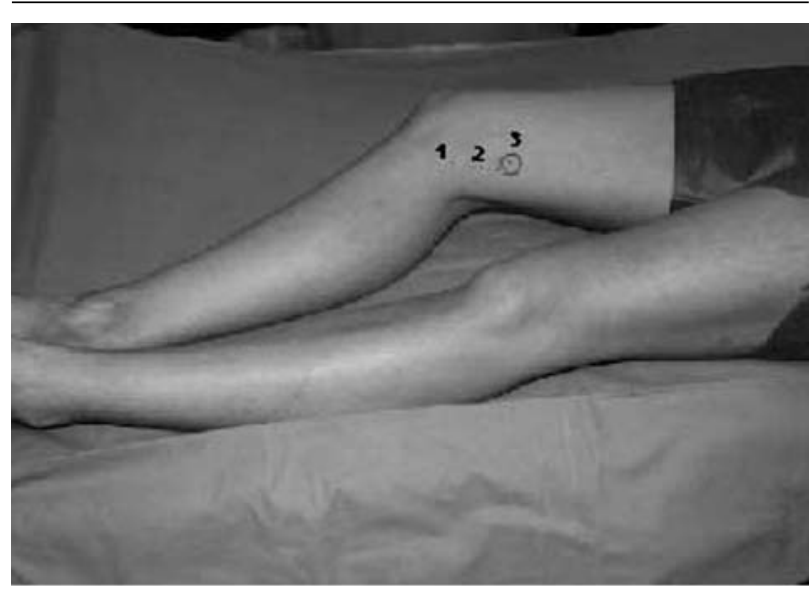

FIGURE 1 Patient position and landmarks

1) Tuberculum adductor; 2) Anterior aspect of the sartorius muscle; 3 ) Puncture site.

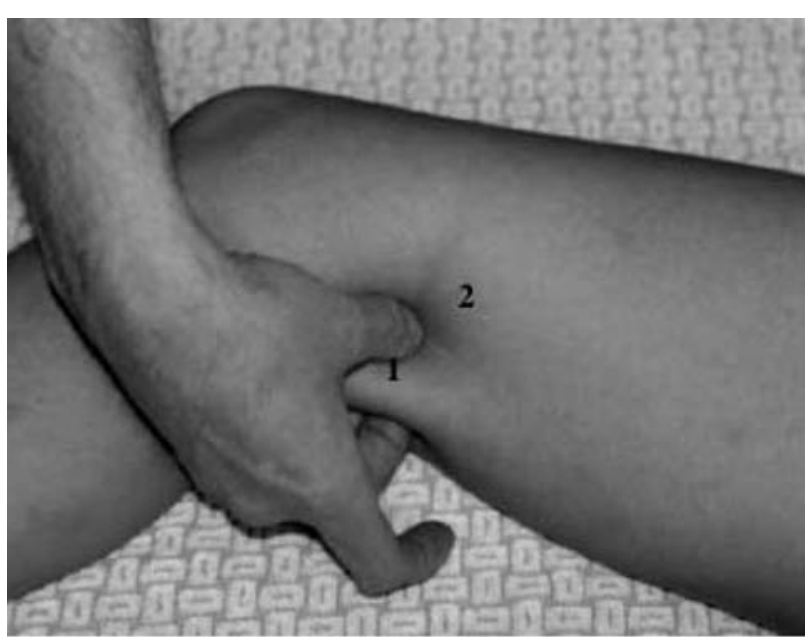

FIGURE 2 Medial side of the right thigh

The thum is inside Jobert's fossa. 1) Sartorious and gracilis muscles held between the medius and the thumb; 2) Vastus medialis muscle.

arch of the adductor magnus muscle and below by the adductor tubercle. ${ }^{10}$ The skin forms the medial wall. Through this groove a medial approach to the superior part of the popliteal fossa is possible. In the position described above, at the level of the centre of Jobert's fossa, inside the popliteal fossa, popliteal vessels are anterior to the sciatic nerve that lies on the posterior wall (Figure 3). The mean distance between these two 


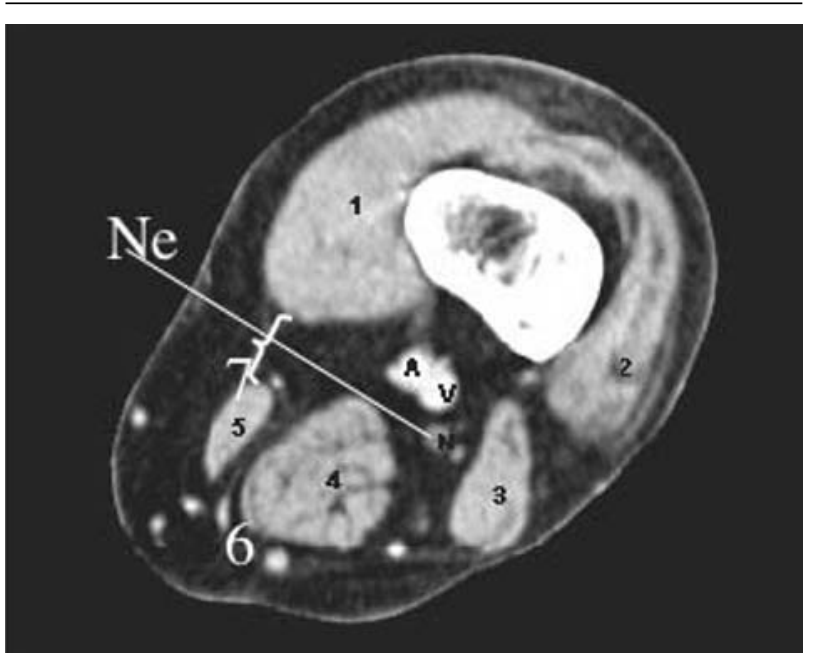

FIGURE 3 Computed tomographic scan of the inferior third of the right thigh in the position described for the block: insertion of the needle ( $\mathrm{Ne}$ ) through Jobert's fossa. 1) Vastus medialis muscle; 2) Vastus lateralis muscle; 3 ) Long head of the biceps femoris muscle; 4) Semimembranosus muscle; 5) Sartorious muscle: 6) Gracilis muscle; 7) Jobert's fossa; $\mathrm{N}=$ sciatic nerve; $\mathrm{A}=$ popliteal arter; $\mathrm{v}=$ popliteal veiny.

structures is $1.2 \mathrm{~cm}$ (range $1-1.6 \mathrm{~cm}$ ). The long saphenous vein runs on the sartorious muscle and the saphenous nerve is divided in two branches above the superior edge of the groove. They are both situated out of the limits of Jobert's fossa.

Landmarks were tested on cadavers with a needle, inserted perpendicularly to the skin, in the middle of Jobert's fossa. This point is located at a mean distance of $6.5 \mathrm{~cm}$ (range $4-7.5 \mathrm{~cm}$ ) above the adductor tubercle. The sciatic nerve is reached at a mean depth of 6 $\mathrm{cm}$ (range $4-8 \mathrm{~cm}$ ).

\section{Clinical results}

The mean age, weight and height of patients, nine men and 11 women, were $39 \mathrm{yr}$ (range 28-65 yr), $73 \mathrm{~kg}$ (range $50-100 \mathrm{~kg}$ ) and $170 \mathrm{~cm}$ (range $162-188 \mathrm{~cm}$ ).

Surgeries for ankle fracture (five patients), foot fracture (five patients), hallux valgus (six patients) and hardware removal (two patients) were performed in the presence ( 15 cases) or absence (three cases) of a tourniquet positioned under the knee, solely under regional anesthesia.

Results from our anatomical study guided the clinical procedure. The patient is placed in the position described previously with the anesthesiologist holding the sartorious and gracilis muscles between the medius and the thumb. The pulp of the thumb is advanced

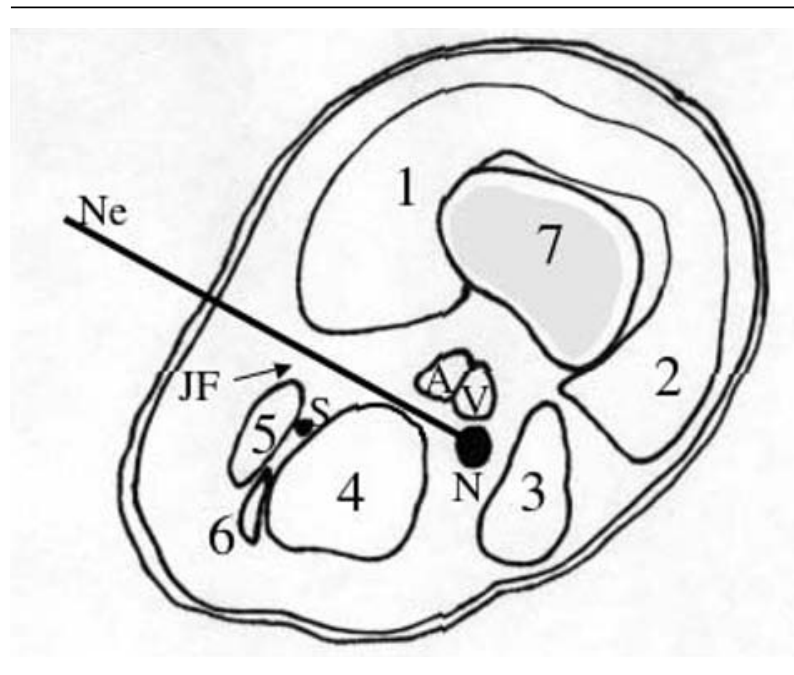

FIGURE 4 Diagram of the inferior third of the right thigh in the position described for the block: insertion of the needle $(\mathrm{Ne})$ through Jobert's fossa. 1) Vastus medialis muscle; 2) Vastus lateralis muscle; 3 ) Long head of the biceps femoris muscle; 4) Semimembranosus muscle; 5) Sartorious muscle; 6) Gracilis muscle; JF = Jobert's fossa; $\mathrm{N}=$ sciatic nerve; $\mathrm{S}=$ saphenous nerve; $\mathrm{A}$ = popliteal artery; $\mathrm{V}=$ popliteal vein.

inside the groove between these muscles and the vastus medialis muscle (Figure 2). A 100-mm needle is inserted perpendicular to the skin, in the middle of the groove indicated by the thumb, anterior to the sartorius muscle. The orientation of the needle remains the same during the entire procedure. The mean distance between the puncture site and the adductor tubercle is $6.18 \mathrm{~cm}$ (range $4-8 \mathrm{~cm}$ ). The mean needle length to reach the sciatic nerve is $6.62 \mathrm{~cm}$ (range $4-9 \mathrm{~cm}$ ). Tibial nerve response is more frequently obtained (Table). Blocks are performed in a mean time of $100 \mathrm{sec}$ (range 50-165 sec). Mean time to obtain a complete motor blockade in the tibial nerve area is $43 \mathrm{~min}$ (range 15-75 $\mathrm{min}$ ) and $30 \mathrm{~min}$ (range 5-60 $\mathrm{min}$ ) in the common peroneal nerve area (Table). The medial cutaneous sural nerve was not blocked in two cases. We obtained a complete motor blockade in 17 patients and a complete sensory blockade in 18 patients out of 20 (Table).

Seven patients reported the experience was unpleasant when the needle crossed the skin. No patient reported pain. The two patients with partial sensory blockade were operated under general anesthesia.

\section{Discussion}

Based on our results, the medial approach to the sciatic nerve is an easy technique that relies on clear landmarks. The popliteal vessels are medial to the sciatic nerve and 
TABLE Clinical results

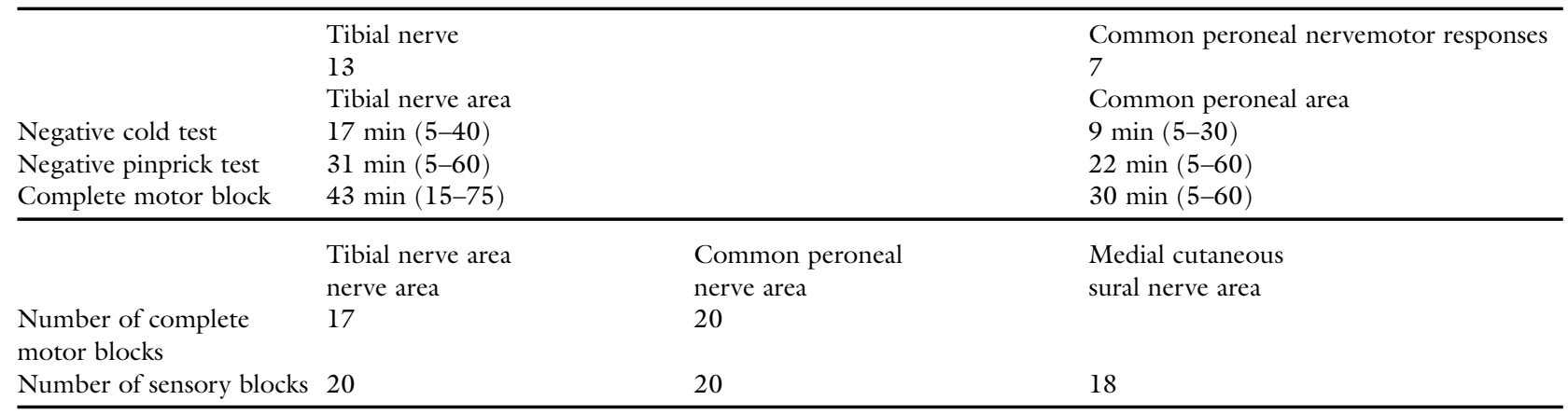

potentially at risk of puncture. Nevertheless, in the position described for this approach (Figure 1), the popliteal vessels are anterior to the pathway of the needle (Figure 3). Thus we did not puncture any vessel. Also, we rarely missed our first attempt to locate the nerve (short time to perform the block). Complete sensory blockade was obtained in 20 patients out of 20 in the tibial and the common peroneal nerve territories. Using the popliteal lateral approach, Zetlaoui also reported that two patients out of 34 experimented a block failure in the territory of the medial cutaneous sural nerve. ${ }^{7}$ In the present study, only three patients had partial motor blockade (Table). Interestingly, these three injections were performed on the common peroneal nerve.

The wide range of values to obtain complete blockade could be related to the limited $(20 \mathrm{~mL})$ volume injected.

The fact that the needle doesn't pass through the muscles is an interesting feature that probably explains the patient's good acceptance of the procedure (Figure 3 ). From a theoretical point of view this anatomical approach should allow to block the saphenous nerve through the trans-sartorial approach before the needle is totally withdrawn. ${ }^{11}$ These new landmarks could also be useful for continuous sciatic nerve block and provide analgesia after ankle and foot surgery. ${ }^{12}$ Position of the catheter could be monitored easily at this site. Finally, since the traumatized lower limb position is often in a position similar to the one described in this approach, the block might be of interest in the emergency room.

Further studies will be required to demonstrate that the sciatic nerve block through the medial approach is an efficient and safe technique.

\section{References}

1 Labat G. Regional Anesthesia: It's Technique and Clinical Application, 2nd ed. Philadelphia: Saunders Company; 1923.
2 Rorie DK, Byer DE, Nelson DO, Sittipong R, Johnson $K A$. Assessment of block of the sciatic nerve in the popliteal fossa. Anesth Analg 1980; 59: 371-6.

3 Gouverneur JM. Sciatic nerve block in the popliteal fossa with atraumatic needles and nerve stimulation. Acta Anaesthesiol Belg 1985; 4: 391-9.

4 Singelyn F, Gouverneur JM, Gribomont BF. Popliteal sciatic nerve block aided by a nerve stimulator: a reliable technique for foot and ankle surgery. Reg Anesth 1991; 16: 278-81.

5 Guardini R, Waldron BA, Wallace WA. Sciatic nerve block: a new lateral approach. Acta Anaesthesiol Scand 1985; 29: 515-9.

6 McLeod DH, Wong DH, Claridge RJ, Merrick PM. Lateral popliteal sciatic nerve block compared with subcutaneous infiltration for analgesia following foot surgery. Can J Anaesth 1994; 41: 673-6.

7 Zetlaoni PJ, Bonaziz H. Lateral approach to the sciatic nerve in the popliteal fossa. Anesth Analg 1998; 87: 79-82.

8 Paqueron X, Bouaziz H, Macalou D, et al. The lateral approach to the sciatic nerve at the popliteal fossa: one or two injections? Anesth Analg 1999; 89: 1221-5.

9 Vloka JD, Hadzic A, Kitain E, et al. Anatomic considerations for sciatic nerve block in the popliteal fossa through the lateral approach. Reg Anesth 1996; 21 : 414-8.

10 Travin AA, Kovanov BB. Surgical Anatomy of the Lower Limb. Moscou: Medicina; 1963.

11 van der Wal M, Lang SA, Yip RW. Transsartorial approach for saphenous nerve block. Can J Anaesth 1993; 40: 542-6.

12 Singelyn FJ, Aye F, Gouverneur JM. Continuous popliteal sciatic nerve block: an original technique of postoperative analgesia after foot surgery. Anesth Analg 1997; 84: $383-6$. 